\title{
Carbohydrate Balance and Accumulation during Development of Near-isogenic Tomato Lines Differing in the AGPase-L1 Allele
}

\author{
Marina Petreikov, Lena Yeselson, Shmuel Shen, Ilan Levin, and Arthur A. Schaffer ${ }^{1}$ \\ Department of Vegetable Crops and Genetics, Agricultural Research Organization, Volcani Center, \\ Bet Dagan, 50250, Israel
}

\author{
Ari Efrati and Moshe Bar \\ Gedera Seed Co, Gedera, Israel
}

\begin{abstract}
ADDITIONAL INDEX wORDS. starch, sugar, TSS, Yield, sink strength, ADP-glucose pyrophosphorylase, Solanum habrochaites, S. lycopersicum

Abstract. Soluble sugar accumulation is a major determinant of tomato (Solanum lycopersicum) fruit quality. One strategy of increasing sugar levels in the mature fruit is via the increase of the transient starch pool in the immature fruit, which is subsequently degraded to contribute to its soluble sugar levels. ADP-glucose pyrophosphorylase [AGPase (E.C. 2.7.7.27)] is a limiting enzyme in starch synthesis and we therefore developed introgression lines of cultivated tomato harboring the wild species (Solanum habrochaites) allele for the regulatory large subunit $\left(L 1^{H}\right)$ of this heterotetrameric enzyme. Comparison of numerous near-isogenic lines of tomato segregating for the $L 1$ allele, during multiple seasons, showed that the wild species allele led to an increase in fruit total soluble solids concentration (TSS) without a concomitant decrease in fruit size. Rather, in practically all lines studied, fruit size increased together with TSS, leading to an even larger increase in TSS $\times$ yield. A comparative developmental study of fruit carbohydrates, starch, and sugars between genotypes showed that the wild species allele led to increases in fruit size, carbohydrate concentration, and carbohydrate content of the whole fruit unit. This was related to a large increase in the transient starch reservoir that, upon degradation, accounted for the subsequent increase in soluble sugars. These results are evidence that modifying fruit sink carbohydrate metabolism via a single rate-limiting enzymatic step can increase the net import of photoassimilate into the fruit.
\end{abstract}

The accumulation of soluble sugars in ripe tomato fruit is perhaps the primary determinant of fruit quality and taste, together with the additional taste components that include acids and volatiles, among other primary and secondary metabolites (Davies and Hobson, 1981; Grierson and Kadar, 1986). Numerous studies have been dedicated to strategies to increase the soluble sugar content of tomatoes, including agrotechnical and genetic approaches (Davies and Hobson, 1981; Ho, 1996; Schaffer et al., 1999). One of the common themes that derive from previous research is that there is a general negative correlation between fruit total soluble solids concentration and yield (Causse et al., 2007; Grandillo et al., 1999), so that increases in TSS do not lead to concomitant increases in tomato solids yield production. This has been widely observed, particularly in studies on the effect of cultivation technologies, such as saline irrigation, in which the increase in sugar concentration is compensated for by decreases in fruit size and yield (Balibrea et al., 1999; Ehret and Ho, 1986).

The sugar content of the fruit is determined by the complex interaction between source and sink metabolism. Modifications of fruit sink metabolism have been attempted to increase what is termed the "sink strength" of the fruit, and subsequently its sugar level. Modifying sugar metabolism in the fruit can

Received for publication 2 Oct. 2008. Accepted for publication 13 Nov. 2008. This research was partially funded by BARD (grant no 3733-05), by the United States-Israel Binational Agricultural Research and Development Fund, and by support from the Gedera Seed Co. (Gedera, Israel).

${ }^{1}$ Corresponding author. E-mail: vcaris@volcani.agri.gov.il. certainly lead to qualitative changes in the sugar content. For example, the sucr locus in tomato controls the partitioning of soluble sugars and determines whether sucrose or hexose is accumulated (Chetelat et al., 1995; Hadas et al., 1995; Miron and Schaffer, 1991; Miron et al., 2002). The wild species allele of the locus leads to a reduction in vacuolar invertase activity in the maturing fruit, allowing for sucrose to accumulate, in contrast to the cultivated tomato in which the vacuolar invertase activity increases during maturity and sucrose cannot accumulate in the vacuole (Klann et al., 1993, Miron et al., 2002).

More importantly, modifying sugar metabolism in the fruit can also lead to quantitative changes in the fruit sugar content. Two examples of this have already been applied in tomato. The tomato LIN5 locus encodes for the fruit expressed apoplastic invertase and a wild species allele for this locus leads to modified enzyme activity in the fruit and subsequent increases in fruit "sink strength" and sugar content, unaccompanied by decreases in fruit yield (Fridman et al., 2002, 2004; Gur and Zamir, 2004). The metabolic rationale behind the strategy of apoplastic invertase modification is that the hydrolysis of translocated sucrose at the point of unloading in the fruit sink can increase the gradient of translocation and hence the net import into the fruit (Fridman et al., 2004; Ho, 1996; Koch, 2004).

Our own previous studies have identified genetic variation for a subunit of the AGPase enzyme that also causes an increase in fruit soluble solids content (Schaffer et al., 2000). The rationale behind this strategy lies in the observation that the developing tomato fruit is a transient starch accumulator and the starch in the immature fruit may serve as a reservoir for 
soluble sugar accumulation during ripening, contributing to the final sugar levels (Dinar and Stevens, 1981; Ho, 1996; Schaffer et al., 2000). Although the starch reservoir of traditional cultivated tomato is small and practically noncontributory, increasing the transient starch pool may significantly impact on sugar levels.

AGPase is a prime candidate for such a modulation because it catalyzes the synthesis of ADP-glucose in the fruit and functions as a limiting enzyme in starch synthesis and accumulation in tomato fruit (Schaffer and Petreikov, 1997; Schaffer et al., 2000), as well as many other plants studied (Ballicora et al., 2004; Preiss and Sivak, 1996; Smith, 2008). In tomato plants, the enzyme functions as a heterotetramer comprised of two large subunits encoded by three possible AgpL genes, and one small subunit encoded by a single AgpSI gene (Chen et al., 1998; Park and Chung, 1998; Petreikov et al., 2006; Schaffer et al., 2000). One particular large subunit, L1, is the major large subunit in the fruit tissue (Chen et al., 1998; Park and Chung, 1998; Petreikov et al., 2006). A set of near isogenic tomato plants was developed from an interspecific cross between the cultivated Solanum lycopersicum (formerly Lycopersicon esculentum Miller) and the wild species Solanum habrochaites (formerly Lycopersicon hirsutum Dunal), differing in the origin of the AgpL1 allele. The fruit carrying the AgpL $1^{H}$ allele (from $S$. habrochaites) is characterized by increased AGPase activity and increased immature fruit starch content, as well as higher TSS in the mature fruit compared with fruit carrying the $A g p L 1^{E}$ allele (from S. lycopersicum) (Petreikov et al., 2006; Schaffer et al., 2000). The mechanism by which this occurs is related to the extended period of gene transcription of the large subunit encoded for by the wild species allele, leading to higher and more stable AGPase activity for an extended period of fruit development (Petreikov et al., 2006).

In the present study, we report the effect of the $A g p L 1^{H}$ allele in tomato of various genetic backgrounds and with fruit of different sizes. In addition, we analyzed the carbohydrate balance of the developing fruit to correlate effects on transient starch accumulation with soluble sugar accumulation. The results indicate that the increase in transient starch accumulation is a valuable strategy for increasing the sink strength of the developing fruit, leading to concomitant increases in fruit size and sugar levels.

\section{Materials and Methods}

Plant material, backgrounds, and introgressions. The near isogenic lines (NILs) of tomato differing in the introgression source of the distal portion of chromosome 1 were developed from the interspecific cross of $S$. habrochaites $(H$, LA1777) and S. lycopersicum and a backcross program to the recurrent $S$. lycopersicum, as described previously (Petreikov et al., 2006; Schaffer et al., 1999, 2000). True-breeding introgressed lines harboring the AGPase-AgpL1 ${ }^{H}$ allele were backcrossed to a number of standard tomato breeding lines of different fruit sizes, and hybrid plants were selfed for the production of $\mathrm{F}_{2}$ populations segregating for the AgpL1 allele. At least seven plants of each genotype were used for the study of the effect of the AgpL1 allele on fruit soluble solids content and size.

Winter-grown plants were sown in September and harvesting took place in January. Plants were grown in the heated greenhouse and were maintained at a minimum night temperature of $15^{\circ} \mathrm{C}$, according to standard growing conditions. Plants grown in the spring season were sown in March and harvesting took place in June. Flowers were allowed to self-pollinate and fruit were harvested when red ripe. For the study of fruit development, line 3011, which segregated for the AgpL1 allele, was used and fruit were sampled at six developmental stages. Eight plants of each genotype were grown during the FallWinter 2007. For the study of the effect of the AgpL1 allele on total plant yield, the determinate $\mathrm{M}-82$ recurrent parent $\left(\operatorname{AgpL1} 1^{E}\right)$ was grown together with two advanced determinate lines, which were products of a $\mathrm{BC}_{2}$ to $\mathrm{M}-82$. Plants were grown in the open field in Gedera, Israel, during the springsummer season. Plants were grown at a spacing of $0.5 \mathrm{~m}$ with 1.5-m rows, according to standard cultivation techniques. Fruit were harvested from each plant when at least $90 \%$ of the fruit reached the red ripe stage. Yield per plant was weighed and TSS and fruit weight were measured on five fruit from each plant.

Genotypic determination of the $\operatorname{AgPL} 1$ allele. Genomic DNA was isolated from young leaves by the Edwards method (Edwards et al., 1991). The determination of the $L 1$ genotype in segregating populations was based on a PCR reaction with specific primers for polymorphism in the promoter region in AgpL $^{H}$ (S. habrochaites accessions DQ322685 and DQ322686) and $A g p L 1^{E}$ (S. lycopersicum accessions DQ322688 and DQ322687) as described in Petreikov et al. (2006). The primers used were: forward AprF (5'CCCTTTAA ATTTCTTAGCCYAC3') and reverse AprR (5'GTTGGAGA TTAGCTGACAATTTC3') with amplicons of 191 and $266 \mathrm{bp}$ for $L 1^{H}$ and $L 1^{E}$, respectively. The PCR reaction consisted of 35 cycles at $94{ }^{\circ} \mathrm{C}$ for $15 \mathrm{~s}, 60^{\circ} \mathrm{C}$ for $15 \mathrm{~s}$, and $72{ }^{\circ} \mathrm{C}$ for $15 \mathrm{~s}$.

STARCH, Sugars, AND TSS. TSS were measured on the extruded fruit juice using a hand-held refractometer (Atago, Tokyo). The soluble sugars (glucose, fructose, and sucrose) were extracted from $1 \mathrm{~g}$ of fresh tissue in hot $80 \%$ alcohol. Following further sample preparation, analysis was performed by high-performance liquid chromatography using Aminex ${ }^{\circledR}$ Fast Carbohydrate Column $(100 \times 7.8 \mathrm{~mm}$, catalog no. $125-$ 0105; BioRad Laboratories, Hercules, CA) as in Petreikov et al. (2006). Starch was measured on the insoluble fraction following ethanol extraction, as previously described (Petreikov et al., 2006). Dry weight was calculated as follows: about half of the whole fruit was oven dried for at least $3 \mathrm{~d}$ at $60^{\circ} \mathrm{C}$, until samples reached a constant weight.

STATISTICAL ANALYSIS. The estimation of standard errors and significant statistical differences were calculated by using Excel (Office 2003; Microsoft, Redmond, WA) and JMP statistical discovery software (version 5.0; SAS Institute, Cary, NC).

\section{Results}

EfFect of L1 ON TSS AND Size of MATURe fruit of DIFFERENT BACKGROUNDS. Over the past years, we developed and analyzed the effect of the $L 1^{H}$ allele in a number of genetic backgrounds of tomato, ranging from cherry size to fruit of $\approx 100 \mathrm{~g}$, in determinate and indeterminate backgrounds, and a summary of the effect on fruit fresh weight and TSS is presented in Table 1. In all cases, plants grown and analyzed were the products of a single selfed heterozygous $L 1^{H E}$ plant, and plants and fruit of the two segregating genotypes were visually indistinguishable. In all cases, genotypes were 
Table 1. The effect of AGPase L1 allele in different genetic backgrounds on tomato fruit fresh weight and total soluble solids (TSS). AgpL1 ${ }^{H}$ and AgpL1E ${ }^{E}$ indicate fruit segregating for the AGPase L1 allele from Solanum habrochaites and S. lycopersicum, respectively.

\begin{tabular}{|c|c|c|c|c|c|c|c|c|c|c|c|c|}
\hline \multirow[b]{2}{*}{ Line no. } & \multirow[b]{2}{*}{ Season/year } & \multicolumn{3}{|c|}{ Fruit wt (g) } & \multicolumn{3}{|c|}{ TSS (\%) } & \multicolumn{3}{|c|}{$\mathrm{TSS} \times$ fruit $\mathrm{wt}$} & \multirow[b]{2}{*}{$s p^{\mathrm{y}}$} & \multirow[b]{2}{*}{$\mathrm{n}^{\mathrm{x}}$} \\
\hline & & $A g p L 1^{H}$ & $A g p L 1^{E}$ & $L 1^{H} / L 1^{E(\%)}$ & $A g p L 1^{H}$ & $\operatorname{AgpL1} 1^{E}$ & $L 1^{H} / L 1^{E(\%)}$ & $A g p L 1^{H}$ & $\operatorname{AgpL1} 1^{E}$ & $L 1^{H} / L 1^{E(\%)}$ & & \\
\hline 4022 & Spring/2004 & $15 \mathrm{~A}^{\mathrm{w}}$ & $14 \mathrm{~A}$ & 107 & $4.9 \mathrm{~B}$ & $4.6 \mathrm{~A}$ & 106 & $74 \mathrm{~B}$ & $64 \mathrm{~A}$ & 114 & $s p+$ & 15 \\
\hline $3255^{z}$ & Spring/2003 & $30 \mathrm{~B}$ & $25 \mathrm{~A}$ & 119 & $7.7 \mathrm{~B}$ & $7.0 \mathrm{~A}$ & 110 & $231 \mathrm{~B}$ & $175 \mathrm{~A}$ & 132 & $s p+$ & 90 \\
\hline 3011 & Spring/2007 & $80 \mathrm{~B}$ & $64 \mathrm{~A}$ & 126 & $5.8 \mathrm{~B}$ & $4.7 \mathrm{~A}$ & 124 & $464 \mathrm{~B}$ & $301 \mathrm{~A}$ & 154 & $s p+$ & 20 \\
\hline 3347 & Winter/2004 & $94 \mathrm{~A}$ & $89 \mathrm{~A}$ & 105 & $5.3 \mathrm{~B}$ & $5.0 \mathrm{~A}$ & 108 & $498 \mathrm{~B}$ & $440 \mathrm{~A}$ & 112 & $s p+$ & 65 \\
\hline 3348 & Winter/2004 & $106 \mathrm{~A}$ & $100 \mathrm{~A}$ & 105 & $4.5 \mathrm{~B}$ & $4.3 \mathrm{~A}$ & 107 & $477 \mathrm{~B}$ & $430 \mathrm{~A}$ & 111 & $s p+$ & 65 \\
\hline
\end{tabular}

${ }^{\mathrm{z}}$ Modified from Petreikov et al., (2006).

${ }^{\mathrm{y}} s p=$ determinate, $s p+=$ indeterminate.

${ }^{\mathrm{x}} \mathrm{n}=$ number of sampled fruit of each genotype.

${ }^{\text {w Letters }}(\mathrm{A}, \mathrm{B})$ within the row indicate a statistical significance difference between genotypes $(P<0.05)$ for each trait separately based on Student's $t$ test.

assigned according to the molecular marker polymorphism in the $L 1$ gene promoter sequences (Fig. 1).

The results indicate that the $L 1^{H}$ allele has a fairly consistent effect, regardless of background. In most cases, TSS and fresh weight are increased; in some cases, only TSS is increased while fresh weight was unaffected. Results were also repeatable in different seasons. Three of the lines were studied in two or three different seasons (Table 2). In one of these lines (line III, the determinate 3414), there were positive effects on fruit weight and fruit TSS in one of the seasons, increases in TSS alone in the second season, while in the last season, of the three, there was no significant effect. In no case, however, did fruit weight decrease in response to an increase in TSS.

For the determinate background in which total yield of the ripe fruit was measured, total fruit yield also increased together with the increase in individual fruit weight (Table 3). In the indeterminate backgrounds, there were no observable negative effects on total cluster weight and there were similarly no decreases in fruit number per cluster (data not presented).

The results were calculated with respect to TSS $\times$ yield and were related to the fruit size of the standard genotype. The results show that the effect of $L 1^{H}$ is irrespective of the background fruit size and shows positive effects in all fruit sizes, from cherry to midsize (100 g) (Table 1). On the average, increases of TSS $\times$ yield are in the range of $20 \%$. In one case (line 3011, the subject of the developmental study, below), the increase in fruit size was around $25 \%$ and, compounded with

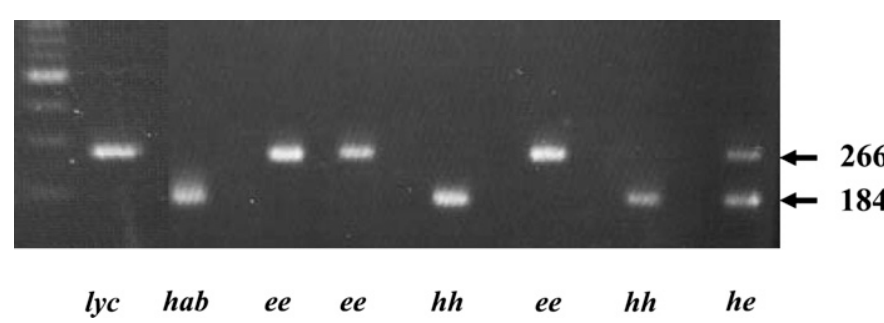

Fig. 1. PCR analysis of AGPaseL1 based on polymorphism in the promoter region. The amplicons (266 and 184 bp for $A g p L 1^{E}$ and $A g p L 1^{H}$ alleles of isogenic lines, respectively) were separated on a $2 \%$ agarose gel and visualized under ultraviolet light after ethidium bromide staining; lyc and hab indicate the parental species Solanum lycopersicum and S. habrochaites, respectively, and ee and $h h$ represent the genotypes of the segregating population. increases in TSS of $25 \%$, showed a large increase in TSS $\times$ fruit weight of over $50 \%$.

EFFECT OF L1 ON CARBOHYDRATE BALANCE DURING FRUIT DEVELOPMENT. A detailed carbohydrate balance during development was carried out on a segregating line, 3011, grown during the winter of 2007-08. This is an indeterminate line with $\approx 6$ fruit per cluster. Fruit were sampled at six stages of development, from small fruitlets to ripe red (Fig. 2).

An increase in fruit size (Fig. 2A) in the $L 1^{H}$ genotype was observed following the rapid increase in fruit size between $\mathrm{mgI}$ and $\mathrm{mgII}$. The $L 1^{H}$ genotype led to an increase in the percentage of dry weight (DW; Fig. 2B) throughout all of fruit development and this was accompanied by a consistently higher starch concentration (Fig. 2C). Other than the earliest stage of development, when variability was relatively high due to the small fruitlet size $(<1 \mathrm{~g})$, the difference in the percentage of DW was accounted for by the differences in starch concentration.

In both genotypes, the starch concentration showed a transient accumulation pattern, declining sharply by the breaker stage. At the mgII stage, the starch concentration of the $L 1^{H}$ genotype was nearly twice that of the $L 1^{E}$ genotype. At the final stages of development, breaker and red, the remaining starch concentration was low and the $L 1^{H}$ genotype began to accumulate soluble sugars at a higher rate than the $L 1^{E}$ genotype (Fig. 2D). At the red stage, the TSS of the $L 1^{H}$ genotype was significantly higher than that of the $L 1^{E}$ genotype (Table 1). At the earliest stages of development, the $L 1^{H}$ genotype had a relatively higher ratio of fructose to glucose, but from the $\mathrm{mgI}$ stage, the ratio of hexoses was unaffected (Fig. 2F).

Viewing the carbohydrate balance on a whole fruit unit basis rather than on a concentration basis sheds further light on the effect of the $L 1^{H}$ allele. The dry weight content per fruit unit (Fig. 2G) was further increased during the latter stages of development due to a compounding of the percentage of DW and fruit unit size at each developmental stage. The most striking effect is seen in the starch content per fruit unit when, at the mature mgII stage, the difference between starch content in the fruit was very large (Fig. $2 \mathrm{H}$ ). The total soluble sugar content of the fruit increases with the degradation of starch content (Fig. 2I), so that the genotypic difference in total nonstructural carbohydrates (soluble sugars and starch) is maintained, and even increases somewhat, from the mgII stage until ripe (Fig. 2J). 
Table 2. The effect of AGPase L1 allele during multiple seasons, in three different genetic backgrounds, on tomato fruit fresh weight and total soluble solids (TSS). AgpL1 ${ }^{H}$ and AgpL $1^{E}$ indicate fruit segregating for the AGPase L1 allele from Solanum habrochaites and S. lycopersicum, respectively.

\begin{tabular}{|c|c|c|c|c|c|c|c|c|c|c|c|c|}
\hline \multirow[b]{2}{*}{$\begin{array}{l}\text { Genetic } \\
\text { background }\end{array}$} & \multirow[b]{2}{*}{ Year } & \multicolumn{3}{|c|}{ Fruit wt (g) } & \multicolumn{3}{|c|}{ TSS (\%) } & \multicolumn{3}{|c|}{ TSS $\times$ fruit wt } & \multirow[b]{2}{*}{$s p^{\mathrm{z}}$} & \multirow[b]{2}{*}{$\mathrm{n}^{\mathrm{y}}$} \\
\hline & & $\operatorname{Agp} L 1^{H}$ & $\operatorname{Agp} L 1^{E}$ & $\begin{array}{c}L 1^{H} / L 1^{E} \\
(\%)\end{array}$ & $\operatorname{AgpL} 1^{H}$ & $\operatorname{Agp} L 1^{E}$ & $\begin{array}{c}L 1^{H} / L 1^{E} \\
(\%)\end{array}$ & $\operatorname{AgpL} 1^{H}$ & $\operatorname{AgpL} 1^{E}$ & $\begin{array}{c}L 1^{H} / L 1^{E} \\
(\%)\end{array}$ & & \\
\hline \multirow[t]{2}{*}{$\overline{I(2324)}$} & 2001 & $45 \mathrm{~B}^{\mathrm{x}}$ & $40 \mathrm{~A}$ & 109 & $5.9 \mathrm{~B}$ & $5.5 \mathrm{~A}$ & 107 & $266 \mathrm{~B}$ & $220 \mathrm{~A}$ & 121 & $s p+$ & $\overline{15}$ \\
\hline & 2006 & $42 \mathrm{~A}$ & $41 \mathrm{~A}$ & 102 & $6.3 \mathrm{~B}$ & $5.7 \mathrm{~A}$ & 111 & $265 \mathrm{~B}$ & $234 \mathrm{~A}$ & 113 & $s p+$ & 18 \\
\hline \multirow[t]{2}{*}{ II (3411) } & 2004 & $62 \mathrm{~A}$ & $60 \mathrm{~A}$ & 103 & $5.8 \mathrm{~B}$ & $5.5 \mathrm{~A}$ & 107 & $360 \mathrm{~A}$ & $330 \mathrm{~A}$ & 109 & $s p+$ & 20 \\
\hline & 2005 & $64 \mathrm{~A}$ & $64 \mathrm{~A}$ & 100 & $5.6 \mathrm{~B}$ & $4.9 \mathrm{~A}$ & 113 & $358 \mathrm{~B}$ & $314 \mathrm{~A}$ & 114 & $s p+$ & 7 \\
\hline & 2005 & $86 \mathrm{~B}$ & $64 \mathrm{~A}$ & 135 & $5.0 \mathrm{~B}$ & $4.4 \mathrm{~A}$ & 113 & $430 \mathrm{~B}$ & $282 \mathrm{~A}$ & 153 & $s p$ & 15 \\
\hline & 2001 & $75 \mathrm{~A}$ & $72 \mathrm{~A}$ & 104 & $4.1 \mathrm{~A}$ & $4.2 \mathrm{~A}$ & 98 & $308 \mathrm{~A}$ & $302 \mathrm{~A}$ & 102 & $s p$ & 32 \\
\hline
\end{tabular}

${ }^{\mathrm{z}_{s}} \mathrm{~s}=$ determinate, $s p+=$ indeterminate.

${ }^{\mathrm{y}} \mathrm{n}=$ number of sampled fruit of each genotype.

'Letters (A,B) within the row designate statistical significance at the $P<0.05$ level using Student's $t$ test.

Table 3. Comparison of tomato total plant yield, total soluble solids (TSS), and average fruit weight between the determinate recurrent parent M-82 and two homozygous determinate $A g p L 1^{H}$ lines. $A g p L 1^{H}$ and $A g p L 1^{E}$ indicate fruit segregating for the AGPase L1 allele from Solanum habrochaites and S. lycopersicum, respectively. Five fruit from each plant were measured for TSS and fruit size.

\begin{tabular}{llcccc}
\hline Line no. & Genotype & $\begin{array}{c}\text { TSS } \\
(\%)\end{array}$ & $\begin{array}{c}\text { Fruit wt } \\
(\mathrm{g})\end{array}$ & $\begin{array}{c}\text { Yield } \\
(\mathrm{kg} / \mathrm{plant})\end{array}$ & $\mathrm{n}^{\mathrm{z}}$ \\
\hline $\mathrm{M}-82$ & AgpL1 $^{E}$ & $3.3 \mathrm{~A}^{\mathrm{y}}$ & $86 \mathrm{~A}$ & $8.00 \mathrm{~A}$ & 18 \\
3276 & AgpL1 $^{H}$ & $5.0 \mathrm{C}$ & $103 \mathrm{~B}$ & $9.08 \mathrm{~A}$ & 25 \\
3277 & AgpL1 $^{H}$ & $4.7 \mathrm{~B}$ & $117 \mathrm{C}$ & $8.39 \mathrm{~A}$ & 26
\end{tabular}

${ }^{\mathrm{z}} \mathrm{n}=$ number of sampled plants of each genotype.

y Letters $(\mathrm{A}-\mathrm{C})$ within the column designate statistical significance at the $P<0.05$ level based on Tukey's multiple comparison test.

\section{Discussion}

The results of this study indicate that it is possible to increase the total sink strength of the tomato fruit by modifying its carbohydrate metabolism, thereby increasing carbohydrate accumulation in the fruit without a concomitant decrease in fruit size. The total fruit carbohydrate pool, and not merely its concentration, can be increased by a change in activity of a single enzyme of carbohydrate metabolism. An arithmetic carbohydrate balance of the whole fruit unit during development shows that at the mgII stage, the $L 1^{H}$ fruit, when $\approx 60 \mathrm{~g}$, contained a reservoir of an additional $600 \mathrm{mg}$ starch, $\approx 1 \%$ of the fruit weight (Fig. 2H), which translates into a pool that can contribute nearly an additional $0.75 \%(600 \mathrm{mg} / 80 \mathrm{~g})$ to the final fruit sugar content of the fruit at its final size of $80 \mathrm{~g}$.

The increase in carbohydrate accumulation is due to a temporal extension of starch synthesis, extending into the major period of fruit expansion, such that the increased starch content in the nearly full size fruit leads to a large carbohydrate reservoir, which, upon degradation, can contribute a significant amount of hexose moieties. Starch synthesis and accumulation may be a particularly effective means of increasing sink strength because the starch molecule is metabolically and osmotically inactive-in effect sequestering the carbohydrate in a metabolically inactive form with little negative impact or feedback on partitioning. In fact, one of the major differences in carbohydrate accumulation patterns due to the LIN5 introgres- sion from Solanum pennellii is the large increase in transient starch in the immature fruit (Baxter et al., 2005), which is likely due to a LIN5-induced increase in sucrose import rate. Interestingly, the increase in starch observed in that study was unaccompanied by increases in starch synthesizing enzyme activity and thus was likely driven by the increased availability of photoassimilate. Accordingly, this would imply that the starch reservoir can be increased by "push or pull" mechanisms. The rate-limiting enzyme AGPase can "pull" carbohydrate into the pool, thereby increasing import, or the increase in import by other means, such as the increased hydrolysis of sucrose, can "push" carbohydrate into the starch pool.

However, this pool is not static, and during the period of fruit development and ripening, there is also continuous sucrose import (Balibrea et al., 2006; Baxter et al., 2005; Damon et al., 1988; Miron and Schaffer, 1991; Walker and Ho, 1977) so that the increase of sugar in the maturing fruit sink is not limited only to the contribution from the degradation of starch. This can be seen by the parallel changes in starch and hexose during the final stages of maturation, from mgII to red. While the increase in hexose content from the mgII stage to the breaker stage is largely accounted for by the decline in starch content (decline of $\approx 750 \mathrm{mg}$ starch and increase of $\approx 850 \mathrm{mg}$ hexose in the $L 1^{H}$ genotype; decline of $\approx 300 \mathrm{mg}$ starch and increase of $\approx 570 \mathrm{mg}$ hexose in the $L 1^{E}$ genotype), the increase in hexose content from the breaker stage to the red stage appears to be largely due to import of photoassimilate because total dry weight of the ripening $L 1^{H}$ fruit increases significantly during this period. This might indicate that the effect of $L 1^{H}$ is not only via the direct synthesis and storage of a large starch reservoir but also, by some unknown mechanism, increasing the sink strength at the final stage, even when starch synthesis is low. In this respect, Balibrea et al. (2006) recently presented evidence suggesting that the wild species of tomato can impart genetic traits for increased sugar import during the ripening stage. The alternative is that photoassimilate transport into the maturing fruit also has a component of transient starch synthesis and increasing the starch synthesis rate even at this late stage when there is no net starch storage may increase the sucrose gradient from source to sink, thereby increasing sink strength. Results presented by N'tchobo et al. (1999) showing that even at maturity, detached tomato fruit can synthesize starch from sucrose applied to the pedicel suggests that there is simultaneous 

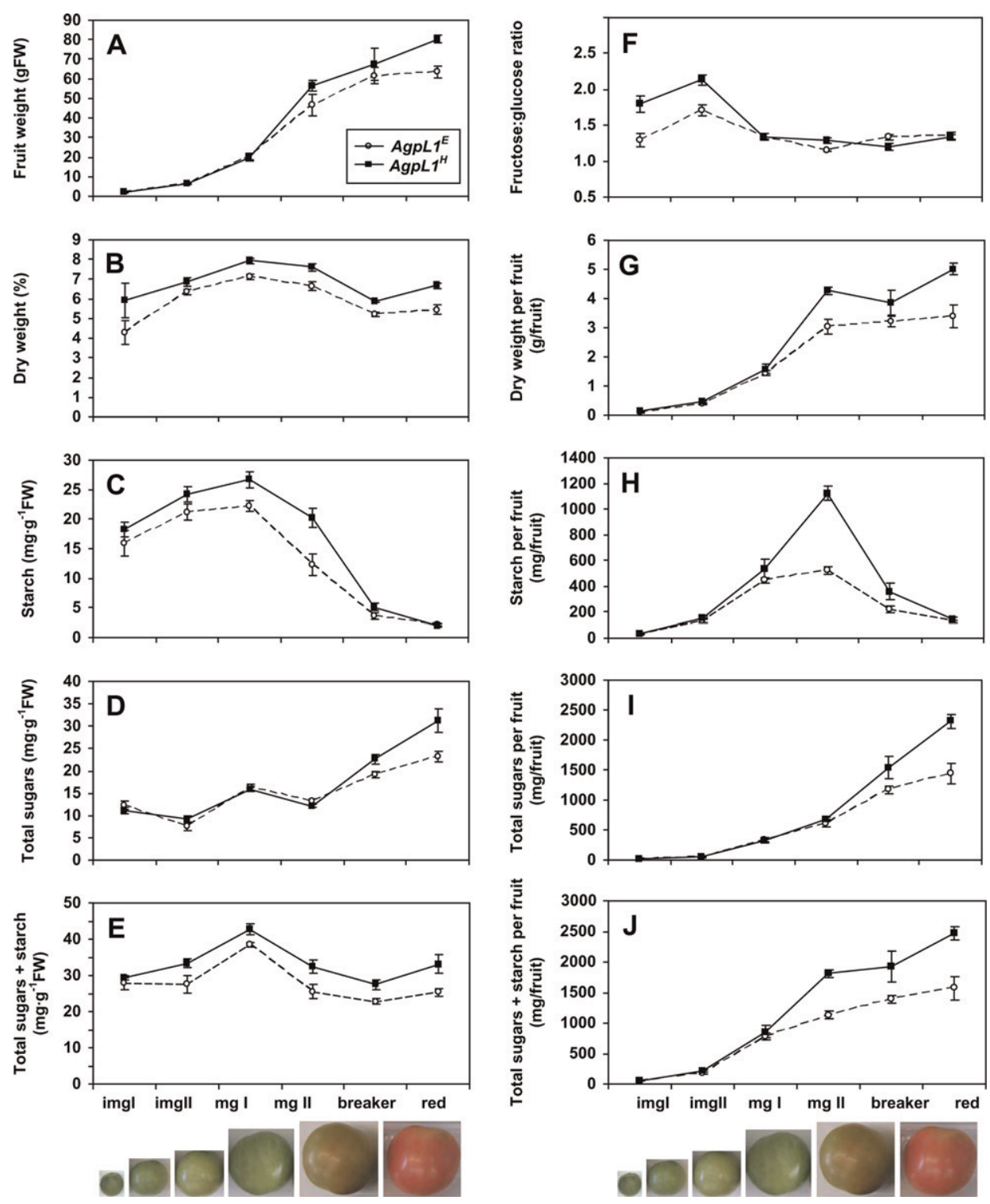

Fig. 2. The Effect of the $L 1$ allele on fruit fresh weight (FW) and carbohydrate content during tomato fruit development. Line 3011 (solid line) segregating for AGPase L1 from Solanum habrochaites $\left(\right.$ AgpL $\left.1^{H}\right)$ and (broken line) S. lycopersicum $\left(\operatorname{AgpL1} 1^{E}\right)$. (A) Fruit fresh weight, (B) percentage of dry weight, (C) starch, (D) total sugars, $(\mathbf{E})$ total sugars plus starch, $(\mathbf{F})$ fructose-to-glucose ratio, and $(\mathbf{G}-\mathbf{J})$ parameters calculated on the base of the whole fruit unit $[(\mathbf{G})$ dry weight, $(\mathbf{H})$ starch, (I) total sugars, and (J) total sugars plus starch]. Error bars represent SE from analysis of six to eight individual fruit.

starch synthesis and degradation even at the later stages of fruit ripening, although other studies indicate that the starch synthesis pathway is low in the mature fruit (Robinson et al., 1988; Schaffer and Petreikov, 1997), even with the $L 1^{H}$ allele (Petreikov et al., 2006; Schaffer and Petreikov, 1997).

We have previously shown that the introgression of the $L 1^{H}$ allele affects only the limiting activity of the AGPase enzyme, whereas the remaining enzymes in the sucrose to starch biosynthetic pathway are unaffected by the $L 1^{H}$ introgression (Schaffer et al., 2000). The mechanism by which the $L 1^{H}$ extends the starch synthesis period is by temporally extending the transcription of the $L 1$ gene that encodes for the large subunit of the heterotetrameric enzyme, AGPase (Petreikov et al., 2006). The small subunit, $S 1$, which comprises the active enzyme, has an extended expression level throughout fruit development and therefore the normally short $L 1$ expression in $L 1^{E}$ genotypes is limiting for the active tetrameric enzyme. By extending L1 expression through introgressing, the natural allelic variant of L1 from a wild species, S. habrochaites, both subunits are available to produce an active enzyme for an extended period of time, which concurs with the increase in fruit sink size from the mgI to mgII. This is a novel example of molecular heterosis (Comings and MacMurray, 2000; Trehan and Gill, 2002) in which the hybrid multimeric enzyme bestows increased starch synthesis in the developing fruit. Because AGPase is a limiting enzyme in starch synthesis in tomato fruit (Schaffer and Petreikov, 1997) as well as in other starch synthesizing tissues (Preiss and Sivak, 1996), increasing its activity during development can lead to an increase in starch. However, increasing activity only when the fruit unit is small would likely not lead to the significant effect, as we report here. It is specifically the temporal extension of activity, such that the whole fruit reservoir increases dramatically, in large part due to the increase in fruit size during this extended period, that is crucial to impacting on the carbohydrate accumulation of tomato fruit.

The effects presented here indicate a fairly consistent effect of the L1 introgression, spanning genetic backgrounds as well as seasons. However, there are cases in which the effect on TSS was not observed. In some cases, this occurred in a background that almost consistently gave significant results (Table 1). This observation underlies the conclusion that there are numerous limiting factors to maximal fruit carbohydrate accumulation and even if AGPase activity in the developing fruit is not limiting, other factors, environmental or genetic, may nevertheless be limiting.

The use of $L 1$ is a good example of a useful marker-assisted selection (MAS) strategy for plant breeding for improved tomato fruit sugar content. The $L 1$ locus is mapped to the distal portion of chr 1-4 (Petreikov et al., 2006; Schaffer et al., 2000). The early analysis of the $S$. pennellii introgression lines (Eshed and Zamir, 1994, 1995) pointed to a QTL for TSS on chromosome 1-4 mapped to a 25-cM region and Causse et al. (2004) further delineated the QTL to the most distal portion of chr 1, in bin 1-J. In the analysis of the S. habrochaites introgression lines, Bernacchi et al. (1998) did not note a TSS QTL on chr 1, but Monforte and Tanksley (2000) did report a 
QTL for TSS but mapped the trait more proximally, to the TG161 marker. Frary et al. (2003) reviewed the data accumulated from different interspecific populations and concluded that the distal portion of chr 1 contains more than one QTL for increased soluble solids. The introgression lines studied here are characterized by small introgressions approximated at 1 cM, between markers TG158 and TG389, distal to TG161 (Petreikov et al., 2006), and the polymorphic marker used is the L1 allele itself.

The wild species of tomato have proven to be a useful source for genetic variability for fruit quality due to variations in genetically determined metabolism that do not exist in the $S$. lycopersicum germplasm. Other examples of loci with alleles derived from wild species that modify sugar content when introgressed into cultivated tomato, without necessarily impacting on the total amount, are sucr, which changes the partitioning between sucrose and hexose (Chetelat et al., 1995; Hadas et al., 1995), and Fgr, which changes the partitioning between fructose and glucose (Levin et al., 2000, 2006). No doubt, further research will uncover additional useful variation.

To date, the only other locus in which genetic variation contributes to a significant impact on total soluble sugar content in the ripe tomato fruit is the LIN5 locus, which encodes for an apoplastic invertase largely expressed in the immature fruit (Fridman et al., 2004). In that case, the allele introgressed from the wild species, $S$. pennellii, increases the soluble sugar content, apparently by encoding for a slightly more kinetically efficient enzyme, and increases the gradient of sucrose from the source to the fruit sink. Together, these two instances show that the strengthening of sink metabolism via a single rate-limiting enzymatic step can increase the net import of photoassimilate into the fruit.

\section{Literature Cited}

Balibrea, M.E., C. Martinez-Andujar, J. Cuartero, M.C. Bolarin, and F. Perez-Alfocea. 2006. The high fruit soluble sugar content in wild type Lycopersicon species and their hybrids with cultivars depends on sucrose import during ripening rather than on sucrose metabolism. Funct. Plant Biol. 33:279-288.

Balibrea, M.E., M. Parra, M.C. Bolarín, and F. Pérez-Alfocea. 1999. Cytoplasmic sucrolytic activity controls tomato fruit growth under salinity. Aust. J. Plant Physiol. 26:561-568.

Ballicora, M.A., A.A. Iglesias, and J. Preiss. 2004. ADP-glucose pyrophosphorylase: A regulatory enzyme for plant starch synthesis. Photosynth. Res. 79:1-24.

Baxter, C.J., F. Carrari, A. Bauke, S. Overy, S.A. Hill, P.W. Quick, A.R. Fernie, and L.J. Sweetlove. 2005. Fruit carbohydrate metabolism in an introgression line of tomato with increased fruit soluble solids. Plant Cell Physiol. 46:425-437.

Bernacchi, D., T. Beck-Bunn, Y. Eshed, S. Inai, J. Lopez, V. Petiard, J. Uhlig, D. Zamir, and S.D. Tanksley. 1998. Advanced backcross QTL analysis in tomato. I. Identification of QTLs for traits of agronomic importance from Lycopersicon hirsutum. Theor. Appl. Genet. 97:381-397.

Causse, M., P. Duffe, M.C. Gomez, M. Buret, R. Damidaux, D. Zamir, A. Gur, C. Chevalier, M. Lemaire-Chamley, and C. Rothan. 2004. A genetic map of candidate genes and QTLs involved in tomato fruit size and composition. J. Expt. Bot. 55:1671-1685.

Causse, M., R. Damidaux, and P. Rousselle. 2007. Traditional and enhanced breeding for quality traits in tomato, p. 153-192. In: M.K. Razdan and A.K. Mattoo (eds.). Genetic improvements of solanaceous crops. Vol. 2: Tomato. Science Publishers, Enfield, NH.

Chen, B.J., H.W. Janes, and T. Gianfagna. 1998. PCR cloning and characterization of multiple ADP-glucose pyrophosphorylase cDNAs from tomato. Plant Sci. 136:59-67.
Chetelat, R.T., J.W. DeVerna, and A.B. Bennett. 1995. Introgression into tomato (Lycopersicon esculentum) of the L. chmielewskii sucrose accumulator gene (sucr) controlling fruit sugar composition. Theor. Appl. Genet. 91:327-333.

Comings, D.E. and J.P. MacMurray. 2000. Molecular heterosis: A review. Mol. Genet. Metab. 71:19-31.

Damon, S., J. Hewitt, M. Nieder, and A.B. Bennett. 1988. Sink metabolism in tomato fruit: II. Phloem unloading and sugar uptake. Plant Physiol. 87:731-736.

Davies, J.W. and G.E. Hobson. 1981. The constituents of tomato fruit the influence of environment, nutrition and genotype. CRC Crit. Rev. Food Sci. Nutr. 15:205-280.

Dinar, M. and M.A. Stevens. 1981. The relationship between starch accumulation and soluble solids content of tomato fruits. J. Amer. Soc. Hort. Sci. 106:415-418.

Edwards, K., C. Johnstone, and C. Thompson. 1991. A simple and rapid method for the preparation of plant genomic DNA for PCR analysis. Nucleic Acids Res. 19:1349.

Ehret, D.L. and L.C. Ho. 1986. The effects of salinity on dry matter partitioning and fruit growth in tomatoes grown in nutrient film culture. J. Hort. Sci. 61:361-367.

Eshed, Y. and D. Zamir. 1994. Introgressions from Lycopersicon pennellii can improve the soluble solids yield of tomato hybrids. Theor. Appl. Genet. 88:891-897.

Eshed, Y. and D. Zamir. 1995. An introgression line population of Lycopersicon pennellii in the cultivated tomato enables the identification and fine mapping of yield-associated QTL. Genetics 141: $1147-1162$.

Frary, A., S. Doganlar, A. Frampton, T. Fulton, J. Uhlig, H. Yates, and S. Tanksley. 2003. Fine mapping of quantitative trait loci for improved fruit characteristics from Lycopersicon chmielewskii chromosome 1. Genome 46:235-243.

Fridman, E., F. Carrari, Y.S. Liu, A.R. Fernie, and D. Zamir. 2004. Zooming in on a quantitative trait for tomato yield using interspecific introgressions. Science 305:1786-1789.

Fridman, E., Y.S. Liu, L. Carmel-Goren, A. Gur, M. Shoresh, T. Pleban, Y. Eshed, and D. Zamir. 2002. Two tightly linked QTLs modify tomato sugar content via different physiological pathways. Mol. Genet. Genomics 266:821-826.

Grandillo, S., D. Zamir, and S.D. Tanksley. 1999. Genetic improvement of processing tomatoes: A 20 year perspective. Euphytica 100:85-89.

Grierson, D. and A. Kader. 1986. Fruit ripening and quality, p. 241280. In: J. Atherton and J. Rudich (eds.). The tomato crop: A scientific basis for improvement. Chapman and Hall, London.

Gur, A. and D. Zamir. 2004. Unused natural variation can lift yield barriers in plant breeding. PLoS Biol. 2:1610-1615.

Hadas, R., A.A. Schaffer, D. Miron, M. Fogelman, and D. Granot. 1995. PCR-generated molecular markers for the invertase gene and sucrose accumulation in tomato. Theor. Appl. Genet. 90:1142-1148.

Ho, L.C. 1996. The tomato, p. 709-728. In: E. Zamski and A.A. Schaffer (eds.). Photoassimilate distribution in plants and crops. Marcel Dekker, New York.

Klann, E., R. Chetelat, and A.B. Bennett. 1993. Expression of acid invertase gene controls sugar composition in tomato (Lycopersicon) fruit. Plant Physiol. 103:863-870.

Koch, K. 2004. Sucrose metabolism: Regulatory mechanisms and pivotal roles in sugar sensing and plant development. Curr. Opin. Plant Biol. 7:235-246.

Levin, I., N. Gilboa, E. Yeselson, S. Shen, and A.A. Schaffer. 2000. $\mathrm{Fgr}$, a major locus that modulates fructose to glucose ratio in mature tomato fruit. Theor. Appl. Genet. 100:256-262.

Levin, I., N. Gilboa, F. Cincarevsky, I. Oguz, M. Petreikov, Y. Yeselson, S. Shen, M. Bar, and A.A. Schaffer. 2006. Epistatic interaction between two unlinked loci derived from introgressions from Lycopersicon hirsutum further modulates the fructose-toglucose ratio in the mature tomato fruit. Isr. J. Plant Sci. 54:215222. 
Miron, D. and A.A. Schaffer. 1991. Sucrose phosphate synthase, sucrose synthase and acid invertase activities in developing fruit of Lycopersicon esculentum Mill. and the sucrose accumulating Lycopersicon hirsutum. Plant Physiol. 95:623-627.

Miron, D., M. Petreikov, N. Carmi, S. Shen, I. Levin, D. Granot, E. Zamski, and A.A. Schaffer. 2002. Sucrose uptake, invertase localization and gene expression in developing fruit of Lycopersicon esculentum and the sucrose-accumulating Lycopersicon hirsutum. Physiol. Plant. 115:35-47.

Monforte, A.J. and S.D. Tanksley. 2000. Fine mapping of a quantitative trait locus (QTL) from Lycopersicon hirsutum chromosome 1 affecting fruit characteristics and agronomic traits: Breaking linkage among QTLs affecting different traits and dissection of heterosis for yield. Theor. Appl. Genet. 100:471-479.

N'tchobo, H., N. Dali, B. Nguyen-Quoc, C.H. Foyer, and S. Yelle. 1999. Starch synthesis in tomato remains constant throughout fruit development and is dependant on sucrose supply and sucrose synthase activity. J. Expt. Bot. 50:1457-1463.

Park, S.-W. and W.-I. Chung. 1998. Molecular cloning and organspecific expression of three isoforms of tomato ADP-glucose pyrophosphorylase gene. Gene 206:215-221.

Petreikov, M., S. Shen, Y. Yeselson, I. Levin, M. Bar, and A.A. Schaffer. 2006. Temporally extended gene expression of the ADPGlc pyrophosphorylase large subunit (AgpL1) leads to increased enzyme activity in developing tomato fruit. Planta 224:14651479.
Preiss, J. and M.N. Sivak. 1996. Starch synthesis in sink and sources, p. 63-96. In: E. Zamski and A.A. Schaffer (eds.). Photoassimilate distribution in plants and crops. Marcel Dekker, New York.

Robinson, N.L., J.D. Hewitt, and A.B. Bennett. 1988. Sink metabolism in tomato fruit. I. Developmental changes in carbohydrate metabolizing enzymes. Plant Physiol. 87:727-730.

Schaffer, A.A. and M. Petreikov. 1997. Sucrose-to-starch metabolism in tomato fruit undergoing transient starch accumulation. Plant Physiol. 113:739-746.

Schaffer, A.A., I. Levin, I. Ogus, M. Petreikov, F. Cincarevsky, E. Yeselson, S. Shen, N. Gilboa, and M. Bar. 2000. ADP-glucose pyrophosphorylase activity and starch accumulation in immature tomato fruit: The effect of a Lycopersicon hirsutum-derived introgression encoding for the large subunit. Plant Sci. 152:135-144. Schaffer, A.A., M. Petreikov, D. Miron, M. Fogelman, M. Spiegelman, Z. Bnei-Moshe, S. Shen, D. Granot, R. Hadas, N. Dai, I. Levine, M. Bar, M. Friedman, M. Pilowsky, N. Gilboa, and L. Chen. 1999. Modification of carbohydrate content in developing tomato fruit. HortScience 34:12-15.

Smith, A.M. 2008. Prospects for increasing starch and sucrose yields for bioethanol production. Plant J. 54:546-558.

Trehan, K.S. and K.S. Gill. 2002. Epigenetics of dominance for enzyme activity. J. Biosci. 27:127-134.

Walker, A.J. and L.C. Ho. 1977. Carbon translocation in the tomato: Carbon import and fruit growth. Ann. Bot. (Lond.) 41:813823. 